\title{
Generalizing the Chiral Self-Assembly of Spheres and Tetrahedra to Non-Spherical and Polydisperse Molecules in $\left(\mathrm{C}_{70}\right)_{x}\left(\mathrm{C}_{60}\right)_{1-x}\left(\mathrm{SnI}_{4}\right)_{2}$
}

\author{
Daniel B. Straus* and R. J. Cava* \\ Department of Chemistry, Princeton University, Princeton, NJ 08544 USA \\ *Authors to whom correspondence should be addressed. Email: dstraus@ princeton.edu, \\ rcava@princeton.edu
}

\begin{abstract}
We describe the spontaneous chiral self-assembly of $\mathrm{C}_{70}$ with $\mathrm{SnI}_{4}$ as well as a mixture of $\mathrm{C}_{60}$ and $\mathrm{C}_{70}$ with $\mathrm{SnI}_{4}$. Macroscopic single crystals with the formula $\left(\mathrm{C}_{70}\right)_{x}\left(\mathrm{C}_{60}\right)_{1-x}\left(\mathrm{SnI}_{4}\right)_{2}(x=0-1)$ are reported. $\mathrm{C}_{60}$, which is spherical, and $\mathrm{C}_{70}$, which is ellipsoidal, form a solid solution in these crystals, and the cubic lattice parameter of the chiral phase linearly increases as $x$ grows from 0 to 1 in accordance with Vegard's law. Our results demonstrate that nonspherical particles and polydispersity are not an impediment to the growth of chiral crystals from high-symmetry achiral precursors, providing a route to assemble achiral particles including colloidal nanocrystals and engineered nanostructures into chiral materials without the need to use external templates.
\end{abstract}


Chiral materials are highly valued in the physical and biological sciences due to their preferential interaction with left- or right-handed circularly polarized light ${ }^{1,2}$ as well as with chiral molecules. ${ }^{3-5}$ They can be used in devices that manipulate light,,${ }^{6,7}$ as stereoselective catalysts, ${ }^{4}$ and as sensors for the detection of biomolecules ${ }^{3}$ and specific enantiomers. ${ }^{5}$ Chiral materials are much more rare than achiral materials, however. Most chiral materials are assembled from molecules with chiral stereocenters, where the chiral molecules themselves are created through stereoselective chemical synthesis. ${ }^{8}$ Chiral materials can also be created through solid-state inorganic materials synthesis as well as through the self-assembly of achiral molecules into chiral crystals. ${ }^{2,8}$ Usually, the achiral molecules that form chiral crystals are floppy or lowsymmetry molecules because helical structures need to form through inter- or intramolecular packing arrangements. $^{9}$

We recently reported macroscopic single crystals of the superatomic ${ }^{10,11}$ chiral van der Waals material $\mathrm{C}_{60}\left(\mathrm{SnI}_{4}\right)_{2}$, formed by the self-assembly of two very high symmetry molecules: icosahedral $\mathrm{C}_{60}$ and tetrahedral $\mathrm{SnI}_{4} \cdot{ }^{12} \mathrm{C}_{60}\left(\mathrm{SnI}_{4}\right)_{2}$ is isostructural to $\mathrm{SrSi}_{2}$, and the $\mathrm{Sn}$ atoms topologically form a chiral cubic three-connected srs net ${ }^{13}$ despite not being chemically bonded to one another. Our discovery demonstrated that high symmetry is not an impediment to 3D chiral self-assembly, creating a new paradigm for chiral materials synthesis.

However, it was unclear whether this chiral self-assembly mechanism would be generalizable to other precursors such as colloidal nanocrystals, or even to other molecules. Unlike $\mathrm{C}_{60},{ }^{14}$ most quasispherical molecules and particles cannot be treated like perfect spheres or spherical shells when assembled into solids. For example, while colloidal nanocrystals can appear to be spherical in transmission electron micrographs, they are faceted and their surface is decorated with ligands. ${ }^{15}$ In addition, most colloidal nanocrystal syntheses result in a polydisperse collection of nanocrystals, ${ }^{15,16}$ and while "magic-size" nanocrystals are a monodisperse alternative, ${ }^{17}$ they are still ligand-capped and non-spherical. Even within the fullerene family, most fullerenes are not spherically symmetric; the second-most common fullerene, 
$\mathrm{C}_{70}$, is an elongated ellipsoid with $\mathrm{D}_{5 \mathrm{~h}}$ point symmetry. ${ }^{18}$ This elongation results in the formation of many different polymorphs of solid $\mathrm{C}_{70}$ with differing degrees of orientational order. ${ }^{19,20}$

Here we demonstrate that elongation of and polydispersity in the "spherical" constituent does not disrupt the chiral self-assembly of quasi-spherical and tetrahedral molecules. Complete replacement of spherical $\mathrm{C}_{60}$ in $\mathrm{C}_{60}\left(\mathrm{SnI}_{4}\right)_{2}$ with ellipsoidal $\mathrm{C}_{70}$ results in the formation of the isostructural material $\mathrm{C}_{70}\left(\mathrm{SnI}_{4}\right)_{2}$, demonstrating that spherical symmetry is not a prerequisite for this type of chiral self-assembly. We also find that despite their different sizes and shapes, a mixture of $\mathrm{C}_{60}$ and $\mathrm{C}_{70}$ with $\mathrm{SnI}_{4}$ self-assembles into a material isostructural to $\mathrm{C}_{60}\left(\mathrm{SnI}_{4}\right)_{2}$. $\mathrm{C}_{60}$ and $\mathrm{C}_{70}$ do not form an ordered superlattice; instead, they form a molecular solid solution with the formula $\left(\mathrm{C}_{70}\right)_{x}\left(\mathrm{C}_{60}\right)_{1-x}\left(\mathrm{SnI}_{4}\right)_{2}$. This discovery indicates that quasi-spherical polydisperse materials with a narrow size distribution, such as colloidal nanocrystals,${ }^{21} \mathrm{can}$ be considered as candidates for chiral self-assembly when combined with appropriately sized tetrahedral structures. $^{22}$

Single crystals of $\mathrm{C}_{70}\left(\mathrm{SnI}_{4}\right)_{2}$ are synthesized similarly to $\mathrm{C}_{60}\left(\mathrm{SnI}_{4}\right)_{2}$ (Supporting Information). ${ }^{12}$ Like $\mathrm{C}_{60}\left(\mathrm{SnI}_{4}\right)_{2}, \mathrm{C}_{70}\left(\mathrm{SnI}_{4}\right)_{2}$ crystallizes in the chiral enantiomorphic space group $\mathrm{P}_{1} 32$ (\#213) (Table S1), and the Flack parameter of -0.04(3) confirms the single crystal is a single chiral domain and that the absolute configuration (handedness) of the crystal has been successfully resolved. ${ }^{23}$ Because neither $\mathrm{C}_{60}$ nor $\mathrm{SnI}_{4}$ contain a stereocenter, it is likely that both left- and right-handed single crystals of $\mathrm{C}_{70}\left(\mathrm{SnI}_{4}\right)_{2}$ will form, so it may also crystallize in the $\mathrm{P} 4332$ (\#212) space group, which is identical to $\mathrm{P} 4_{1} 32$ except for its handedness. The $\mathrm{C}_{70}$ molecule is modeled as a rigid body with six-fold disorder across symmetry elements. The chiral $4_{1}$ screw axis of $\mathrm{C}_{70}\left(\mathrm{SnI}_{4}\right)_{2}$ is shown in Figure 1A with $\mathrm{C}_{70}$ disorder omitted; a similar image with disorder is shown in Figure S1, and the asymmetric unit is shown in Figure $\mathrm{S} 2$. The structure of $\mathrm{C}_{60}\left(\mathrm{SnI}_{4}\right)_{2}$ is shown in Figure 1B for comparison. ${ }^{12}$ Details of the crystal structure refinement are given in Supporting Information. At room temperature, $\mathrm{C}_{70}$ is rotating within the crystal, which we observe through a lack of resolved atomicity in the structural model derived from the single crystal diffraction data. Like in $\mathrm{C}_{60}\left(\mathrm{SnI}_{4}\right)_{2}$, the location of individual carbon atoms cannot be resolved. ${ }^{12}$ We are not able to determine whether $\mathrm{C}_{70}$ 
freely rotates or whether it there is some degree of dynamic or static orientational order such that $\mathrm{C}_{70}$ preferentially rotates about its long axis.

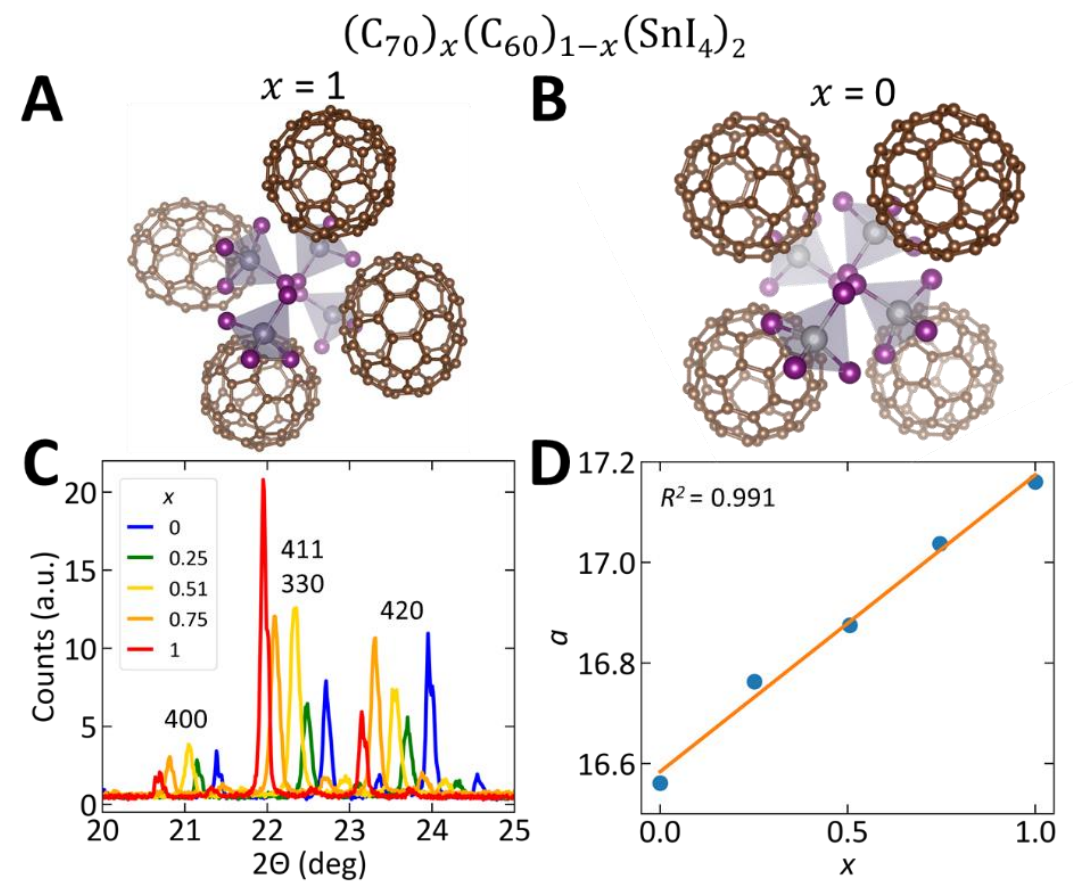

Figure 1: Structure of $\left(\mathbf{C}_{\mathbf{7 0}}\right)_{\boldsymbol{x}}\left(\mathbf{C}_{\mathbf{6 0}}\right)_{1-x}\left(\mathbf{S n I}_{\mathbf{4}}\right)_{2}$. A) Depiction of the chiral $4_{1}$ screw axis of $\mathbf{C}_{70}\left(\mathrm{SnI}_{4}\right)_{2}$ (disordered carbons omitted) with $\mathrm{B}$ ) structure of $\mathrm{C}_{60}\left(\mathrm{SnI}_{4}\right)_{2}$ for comparison. C) Powder X-ray diffraction pattern of $\left(\mathrm{C}_{70}\right)_{x}\left(\mathrm{C}_{60}\right)_{1-x}\left(\mathrm{SnI}_{4}\right)_{2}$ solid solutions. D) lattice parameter $a$ extracted from Le Bail refinements of powder X-ray diffraction patterns. A linear fit to the observations is shown in orange. B) reprinted from ref 12 .

Compared to $\mathrm{C}_{60}, \mathrm{C}_{70}$ is identical in width but is elongated owing to the addition of five hexagons around its girth. ${ }^{24}$ There are many polymorphs of solid $\mathrm{C}_{70}$, including a face-centered cubic phase as well as two hexagonally-close-packed phases, one with the long axes of $\mathrm{C}_{70}$ aligned and one with random orientations of the molecule. ${ }^{20}$ In the FCC phase where the $\mathrm{C}_{70}$ molecules exhibit full orientational disorder, the lattice constant is $14.96 \mathrm{~A}$, which indicates that the effective van der Waals radius of $\mathrm{C}_{70}$ is $5.29 \AA$, $5.6 \%$ larger than the $5.01 \AA$ radius of $\mathrm{C}_{60}{ }^{19}$ Based on the effective radius of $\mathrm{SnI}_{4}$ of $2.95 \AA$, ${ }^{12}$ the radius ratio $\gamma$ of $\mathrm{C}_{70}\left(\mathrm{SnI}_{4}\right)_{2}$ is 0.56 . This ratio is similar to the ratio for $\mathrm{SrSi}_{2}(\gamma=0.55)$ as well as for $\mathrm{C}_{60}\left(\mathrm{SnI}_{4}\right)_{2}(\gamma$ $=0.59$ ), consistent with these three materials being isostructural and indicating that that the larger size of $\mathrm{C}_{70}$ compared to $\mathrm{C}_{60}$ does not significantly change $\gamma$. The fact that $\mathrm{C}_{70}\left(\mathrm{SnI}_{4}\right)_{2}$ and $\mathrm{C}_{60}\left(\mathrm{SnI}_{4}\right)_{2}$ are both 
isostructural to $\mathrm{SrSi}_{2}$ despite the difference in size and shape of the fullerene supports our previous conclusion that the chirality is templated by $\mathrm{SnI}_{4}$ and not by the fullerene. ${ }^{12}$

By mixing $\mathrm{C}_{70}$ and $\mathrm{C}_{60}$ in the precursor solution and varying the fraction $x$ of $\mathrm{C}_{70}$, we synthesize single crystals of the mixed fullerene variant $\left(\mathrm{C}_{70}\right)_{x}\left(\mathrm{C}_{60}\right)_{1-x}\left(\mathrm{SnI}_{4}\right)_{2}(\mathrm{x}=0-1)$, which is isostructural to both $\mathrm{C}_{60}\left(\mathrm{SnI}_{4}\right)_{2}$ and $\mathrm{C}_{70}\left(\mathrm{SnI}_{4}\right)_{2}$. Asymmetric units of the single crystal structures are shown in Figures $\mathrm{S} 3$ 5, and refinement statistics are given in Tables S2-4. As $x$ increases from 0 to 1 , the cubic lattice constant $a$ linearly increases from that of $\mathrm{C}_{60}\left(\mathrm{SnI}_{4}\right)_{2}$ to that of $\mathrm{C}_{70}\left(\mathrm{SnI}_{4}\right)_{2}$ (Figure 1C-D), demonstrated by the shift of reflections in the $\mathrm{X}$-ray diffraction patterns to lower angle. This indicates that $\left(\mathrm{C}_{70}\right)_{x}\left(\mathrm{C}_{60}\right)_{1-x}\left(\mathrm{SnI}_{4}\right)_{2}$ forms a solid solution where $\mathrm{C}_{60}$ and $\mathrm{C}_{70}$ partially occupy the same crystallographic site in a random fashion. ${ }^{25}$ (At a given site, the probability of finding $\mathrm{C}_{70}$ is $x$ and $\mathrm{C}_{60}$ is $1-x$, and there is no long-range ordering of $\mathrm{C}_{60}$ and $\mathrm{C}_{70}$.) The lattice parameter of the resulting material varies linearly with composition, in accordance with Vegard's law for solid solutions. ${ }^{26}$ Synthesized precession images of the $h k 0$ plane from single crystal X-ray diffraction measurements reveal that there are no superlattice reflections in our solid solutions (Figure 2), confirming that $\mathrm{C}_{60}$ and $\mathrm{C}_{70}$ form a molecular solid solution in $\left(\mathrm{C}_{70}\right)_{x}\left(\mathrm{C}_{60}\right)_{1-x}\left(\mathrm{SnI}_{4}\right)_{2}$.
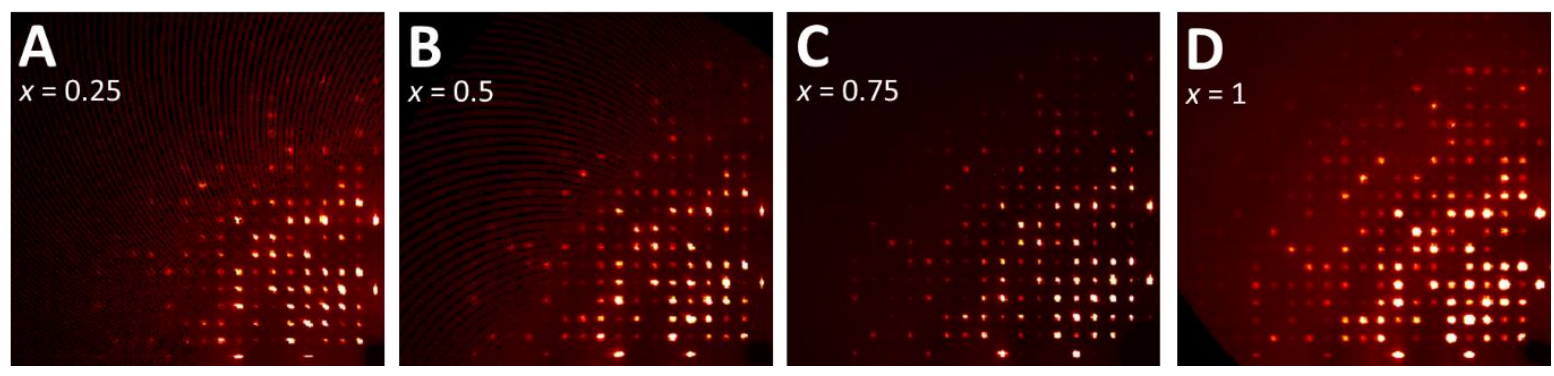

Figure 2: Single-crystal diffraction. Synthesized single crystal $X$-ray diffraction precession images of one quadrant of the $h k 0$ plane for crystals of $\left(\mathrm{C}_{70}\right)_{x}\left(\mathrm{C}_{60}\right)_{1-x}\left(\mathrm{SnI}_{4}\right)_{2}$ with $\left.\left.\left.\mathrm{A}\right) \mathrm{x}=0.25, \mathrm{~B}\right) \mathrm{x}=0.5, \mathrm{C}\right) \mathrm{x}=$ 0.75 , and $\mathrm{D}) \mathrm{x}=1$.

In conclusion, the synthesis of $\mathrm{C}_{70}\left(\mathrm{SnI}_{4}\right)_{2}$ demonstrates that a perfect sphere is not needed for the chiral self-assembly of quasi-spherical and tetrahedral molecules into macroscopic single crystals. Furthermore, the polydispersity of $\mathrm{C}_{60}$ and $\mathrm{C}_{70}$ in the $\left(\mathrm{C}_{70}\right)_{x}\left(\mathrm{C}_{60}\right)_{1-x}\left(\mathrm{SnI}_{4}\right)_{2}$ solid solution does not disrupt 
this chiral self-assembly mechanism, despite the $5.6 \%$ size difference between $\mathrm{C}_{60}$ and $\mathrm{C}_{70}$. These results confirm our hypothesis that the tetrahedral shape of $\mathrm{SnI}_{4}$ is responsible for templating the chiral structure because the assembly process is insensitive to the ellipsoidal particles and polydispersity. Our results demonstrate that the spontaneous chiral self-assembly of polydisperse and imperfect particles such as colloidal nanocrystals ${ }^{21}$ and engineered nanostructures ${ }^{27}$ should be possible when paired with an appropriately sized tetrahedral co-crystallizer.

\section{Supporting Information}

Methods, additional depictions of crystal structures (Figures S1-S5), tabulated crystal data and structure refinement details (Tables S1-S4). (PDF)

Single crystal X-ray diffraction structures and structure factors have been deposited at the Cambridge Crystallographic Data Centre under deposition numbers 2072467-2072470 and are accessible at https://www.ccdc.cam.ac.uk/structures/ as well as well as in the Supporting Information.

Crystal structure of $\mathrm{C}_{70}\left(\mathrm{SnI}_{4}\right)_{2}(\mathrm{CIF})$

Crystal structure of $\left(\mathrm{C}_{70}\right)_{0.25}\left(\mathrm{C}_{60}\right)_{0.75}\left(\mathrm{SnI}_{4}\right)_{2}(\mathrm{CIF})$

Crystal structure of $\left(\mathrm{C}_{70}\right)_{0.5}\left(\mathrm{C}_{60}\right)_{0.5}\left(\mathrm{SnI}_{4}\right)_{2}(\mathrm{CIF})$

Crystal structure of $\left(\mathrm{C}_{70}\right)_{0.75}\left(\mathrm{C}_{60}\right)_{0.25}\left(\mathrm{SnI}_{4}\right)_{2}(\mathrm{CIF})$

\section{Acknowledgments}

We thank Dr. Robert A. Pascal and Dr. Weiwei Xie for helpful discussion on modeling $\mathrm{C}_{60}$ and $\mathrm{C}_{70}$ in crystal structures. This work is supported by the Gordon and Betty Moore Foundation as part of the EPiQS initiative under grant GBMF9066.

\section{Notes}

The authors declare no competing financial interest.

\section{References}

(1) Ma, W.; Xu, L.; De Moura, A. F.; Wu, X.; Kuang, H.; Xu, C.; Kotov, N. A. Chiral Inorganic Nanostructures. Chem. Rev. 2017, 117, 8041-8093.

(2) Liu, M.; Zhang, L.; Wang, T. Supramolecular Chirality in Self-Assembled Systems. Chem. Rev. 2015, 115, 7304-7397.

(3) Torsi, L.; Farinola, G. M.; Marinelli, F.; Tanese, M. C.; Omar, O. H.; Valli, L.; Babudri, F.; Palmisano, F.; Zambonin, P. G.; Naso, F. A sensitivity-enhanced field-effect chiralsensor. Nat. Mater. 2008, 7, 412-417.

(4) Soai, K.; Osanai, S.; Kadowaki, K.; Yonekubo, S.; Shibata, T.; Sato, I. d - and 1 -Quartz-Promoted Highly Enantioselective Synthesis of a Chiral Organic Compound. J. Am. Chem. Soc. 1999, 121, $11235-11236$. 
(5) Hendry, E.; Carpy, T.; Johnston, J.; Popland, M.; Mikhaylovskiy, R. V.; Lapthorn, A. J.; Kelly, S. M.; Barron, L. D.; Gadegaard, N.; Kadodwala, M. Ultrasensitive detection and characterization of biomolecules using superchiral fields. Nat. Nanotechnol. 2010, 5, 783-787.

(6) Gansel, J. K.; Thiel, M.; Rill, M. S.; Decker, M.; Bade, K.; Saile, V.; Von Freymann, G.; Linden, S.; Wegener, M. Gold helix photonic metamaterial as broadband circular polarizer. Science 2009, $325,1513-1515$.

(7) Zhang, M.; Pacheco-Peña, V.; Yu, Y.; Chen, W.; Greybush, N. J.; Stein, A.; Engheta, N.; Murray, C. B.; Kagan, C. R. Nanoimprinted Chiral Plasmonic Substrates with Three-Dimensional Nanostructures. Nano Lett. 2018, 18, 7389-7394.

(8) Flack, H. D. Chiral and achiral crystal structures. Helv. Chim. Acta 2003, 86, 905-921.

(9) Matsuura, T.; Koshima, H. Introduction to chiral crystallization of achiral organic compounds: Spontaneous generation of chirality. J. Photochem. Photobiol. C Photochem. Rev. 2005, 6, 7-24.

(10) Roy, X.; Lee, C.-H.; Crowther, A. C.; Schenck, C. L.; Besara, T.; Lalancette, R. A.; Siegrist, T.; Stephens, P. W.; Brus, L. E.; Kim, P.; Steigerwald, M. L.; Nuckolls, C. Nanoscale Atoms in SolidState Chemistry. Science 2013, 341, 157-160.

(11) Doud, E. A.; Voevodin, A.; Hochuli, T. J.; Champsaur, A. M.; Nuckolls, C.; Roy, X. Superatoms in materials science. Nat. Rev. Mater. 2020, 5, 371-387.

(12) Straus, D. B.; Cava, R. J. Self-Assembly of a Chiral Cubic Three-Connected Net from the High Symmetry Molecules C 60 and SnI 4. J. Am. Chem. Soc. 2020, 142, 13155-13161.

(13) Hyde, S. T.; O'Keeffe, M.; Proserpio, D. M. A short history of an elusive yet ubiquitous structure in chemistry, materials, and mathematics. Angew. Chemie - Int. Ed. 2008, 47, 7996-8000.

(14) Fischer, J. E.; Heiney, P. A. Order and disorder in fullerene and fulleride solids. J. Phys. Chem. Solids 1993, 54, 1725-1757.

(15) Murray, C. B.; Kagan, C. R.; Bawendi, M. G. Synthesis and Characterization of Monodisperse Nanocrystals and Close-Packed Nanocrystal Assemblies. Annu. Rev. Mater. Sci. 2000, 30, 545-610.

(16) Hens, Z.; De Roo, J. Atomically Precise Nanocrystals. J. Am. Chem. Soc. 2020, 142, 15627-15637.

(17) Jin, R.; Zeng, C.; Zhou, M.; Chen, Y. Atomically Precise Colloidal Metal Nanoclusters and Nanoparticles: Fundamentals and Opportunities. Chem. Rev. 2016, 116, 10346-10413.

(18) Diederich, F.; Ettl, R.; Rubin, Y.; Whetten, R. L.; Beck, R.; Alvarez, M.; Anz, S.; Sensharma, D.; Wudl, F.; Khemani, K. C.; Koch, A. The higher fullerenes: Isolation and characterization of C76, C84, C90, C94, and C70O, an oxide of D5h-C70. Science 1991, 252, 548-551.

(19) Fischer, J. E. Structure and dynamics of solid C60 and its intercalation compounds. Mater. Sci. Eng. B 1993, 19, 90-99.

(20) Verheijen, M. A.; Meekes, H.; Meijer, G.; Bennema, P.; de Boer, J. L.; van Smaalen, S.; van Tendeloo, G.; Amelinckx, S.; Muto, S.; van Landuyt, J. The structure of different phases of pure C70 crystals. Chem. Phys. 1992, 166, 287-297.

(21) Shevchenko, E. V; Talapin, D. V; Kotov, N. a; O'Brien, S.; Murray, C. B. Structural diversity in binary nanoparticle superlattices. Nature 2006, 439, 55-59.

(22) Narayanan, R.; El-Sayed, M. A. Effect of Nanocatalysis in Colloidal Solution on the Tetrahedral and Cubic Nanoparticle SHAPE: Electron-Transfer Reaction Catalyzed by Platinum Nanoparticles. 
J. Phys. Chem. B 2004, 108, 5726-5733.

(23) Flack, H. D. On enantiomorph-polarity estimation. Acta Crystallogr. Sect. A Found. Crystallogr. 1983, 39, 876-881.

(24) Bodner, M.; Patera, J.; Szajewska, M. Breaking of icosahedral symmetry: C60to C70. PLoS One 2014, 9, 1-5.

(25) Lusi, M. A rough guide to molecular solid solutions: design, synthesis and characterization of mixed crystals. CrystEngComm 2018, 20, 7042-7052.

(26) Vegard, L. Die Konstitution der Mischkristalle und die Raumfullung der Atome. Zeitschrift fur Phys. 1921, 5, 17-26.

(27) Zhang, M.; Guo, J.; Yu, Y.; Wu, Y.; Yun, H.; Jishkariani, D.; Chen, W.; Greybush, N. J.; Kübel, C.; Stein, A.; Murray, C. B.; Kagan, C. R. 3D Nanofabrication via Chemo-Mechanical Transformation of Nanocrystal/Bulk Heterostructures. Adv. Mater. 2018, 30, 1800233. 